\title{
Different Paths, Same Destination: A Case Study of the 2002 Amendment to the Education Act for Chinese Minorities in Malaysia
}

\author{
Charissa Soek Yee Chan (St. Margaret's Primary School, \\ Singapore)
}

\begin{abstract}
This article describes the effects and implications of the 2002 Amendment to the Education Act for the ethnic Chinese community, through exploring the challenges that the policy pose for Chinese school and education, as well as investigating the responses of the different stakeholders in Chinese community toward the change in policy. A case study approach was adopted for this study. Surveys (of students and parents), discussions with educators, and document analysis of textbooks and newspapers were carried out. Findings indicated that this policy had negative implications for mother tongue education in Malaysia, resulting in a huge overhaul of the Chinese primary school and educational system. This assimilatory policy seeks to undermine the maintenance of ethnic Chinese minority's heritage and identity.
\end{abstract}

\begin{abstract}
Résumé
Cet article décrit les effets et les implications soulevés par l'amendement de la Loi Educative en 2002 pour la communauté chinoise. Il explore de ce fait les défis que cette loi pose aux écoles et à l'éducation chinoise en général, et explique les solutions que les différents acteurs de la communauté chinoise ont adoptées afin de répondre aux changements que cette loi implique. La recherche repose sur une étude de cas, raison pour laquelle l'auteure a effectué des sondages auprès des étudiants et des parents, a mené des discussions avec les professeurs et a analysé des livres de cours et quelques journaux. Ses recherches ont démontré que cette loi avait des implications négatives pour l'éducation en langue native en Malaisie, ce qui a mené à une restructuration importante non seulement de l'école primaire chinoise mais également du système éducatif dans son ensemble. Cette politique d'assimilation cherche à affaiblir la présence des minorités ethniques chinoises et leur identité.
\end{abstract}

\section{INTRODUCTION}

Prior to the 2002 Amendment to the Education Act, Malaysia (a multiethnic country) is one of the few postcolonial countries that sought to reduce the role and status of colonial English in the aftermath of independence. It aggressively pursued a nation-building program that promoted an indigenous languageMalay - as the national and dominant language in all official and formal spheres (Deng \& Gopinathan, 2006, p.612)

One of the major initiatives under this attempt to redress historical inequalities is the implementation of a bilingual education program, in which the Malay language is promoted as the main Medium of Instruction (MOI). Colonial English was relegated to a secondary position (Gills, 2005, p.249). The quadruple system of schooling (English, Malay, Chinese and Tamil) that existed previously was gradually replaced by a parallel system of schooling -the 
"national" versus the "national-type" schools, the latter referring to Chinese or Tamil schools for those ethnic minority groups (Mother Tongue as MOI for all subjects with the exception of English and Malay as core subjects). As the Malaysian Constitution recognizes the linguistic and educational rights of the ethnic Chinese and Tamil minorities, they have the right to use their own language and have access to education in their mother tongue. However, as a minority, the Chinese have always feared that "the majority ethnic group intends to nation-build by assimilating them into the dominant identity of the majority group" (Collins, 2005, p.569). This fear is not unfounded, as this study would demonstrate.

\section{THEORETICAL FRAMEWORK}

For an in-depth understanding of the study, given the unique characteristics of the post-colonial Asian country on which this study is focused, pertinent minority education literature is reviewed. Firstly, the link between language and minority identity is presented, framed within the larger context of nation building. The continued survival of minority languages (and consequently, ethnic minority identity) is often dependent on the rights of the minority groups and the language policies implemented by the dominant group.

\section{Language and Identity}

As Baker (2006) states, language is an important symbol of national identity and helps to create a consciousness of "belonging to an imagined separate people, located in a defined territory, bound by a belief in a common culture and history, with common institutions and desiring to achieve or maintain political autonomy" (p.83). In a multiethnic society especially, language assumes an even more important role in gaining and sustaining group cohesion for the purposes of creating a national identity and common consciousness. However, concerns about preserving their particular identity from perceived external threats often elicit in minority ethnic groups a desire to maintain their languages and cultures (Chandler, 1992, p.21). Consequently, "illiteracy of resistance" will be instituted by the minority ethnic group itself, which "wishing to safeguard its language and culture, and fearing assimilation, turns in on itself and rejects the form of education imposed by the majority group" (Van Deven, 2006, p.41).

Often however, ethnic minority groups are forced to assimilate through the 'stick and carrot' approach. In addition to or instead of using the stick approach, the dominant group has increasingly adopted the 'carrot' approach, mediated through ideological and psychological means (Skutnabb-Kangas, 2000, p.130-1). In such situations, "illiteracy of oppression" (a direct consequence of the process of assimilation or integration at work) usually occurs, in which the minority ethnic group's identity and means of resistance are often slowly destroyed (Van Deven, 2006, p.42). 


\section{Language, Nation building and National Identity}

Minority languages represent important markers of ethnic identity, but the maintenance of ethnic identities has often been seen as contrary to the unity of the nation (Baker, 2006, p.83). This view, based on the "language as a problem" orientation, is a widespread belief among many newly independent or developing nations with a multi-ethnic population. The "language as a problem" orientation argues that "perpetuating language minorities and language diversity may cause less integration, less cohesiveness, more antagonism and more conflict in society" (p. 384). For newly independent or developing countries, the outcomes of language diversity are contradictory to the goals of nation-building (as characterized by political, economic and social stability) which they are aiming for. A crucial step to forging a national identity, from among the many different ethnic identities, is to create a common culture, through imposing a common language (usually the dominant language) (Kee, 1971, p.73). Thus, attempts have been made by governments (that espouse a "language as a problem" orientation) to eradicate the minority languages or restrict the domains in which they are used, and instead establish the majority languages in their place, by means of education and compulsory use of the majority language in public and official life (Baker, 2006, p.83).

Contrary to the language as a problem orientation held by most newly independent or developing countries, some academicians advocate for a "language as a resource" orientation towards nation-building. Underlying this orientation is the belief that linguistic diversity is a resource that can be "exploited for cultural, spiritual and educational growth as well as for economic, commercial and political gain" (Baker, 2006, p.391). It is evident that most "language as a resource" proponents have reduced language to a mere economic commodity, which when used to one's advantage, provides access to goods and services.

\section{Language Rights}

A third orientation to language is the "language as a right" orientation (Baker, 2006, p.386). On a collective level, language rights imply that minority groups have the right to enjoy and develop their language, which entails the right to establish schools and other educational institutions, with control of curricula and teaching in their own languages. Essentially, language rights are rights to protection and rights to participation.

Often, struggles over language rights ensue when minority ethnic groups perceive their identity to be threatened and that they are in danger of being assimilated. Consequently, some minority groups will start demanding their rights (both language and otherwise), mobilize as a group through stressing "the importance of the mother tongue, as a necessary (often primordial) bond between the group's members, and between the group and its history and 
culture" (Skutnabb-Kangas, 2000, p.640). Minority ethnic groups whose demands for language rights have not been met have often been forced into either multilingualism or into monolingualism (in which the dominant group's language has replaced their mother tongue). The lack of linguistic rights often prevents a minority ethnic group from achieving educational, economic and political equality with other groups. (p.43).

\section{Medium of instruction policies}

Given that linguistic rights are not enjoyed by all minority ethnic groups, languages in societies have varying status, leading to the constitution of linguistic hierarchies (Lindgren, 2000, p.40). Thus, minority ethnic groups, defined on the basis of their mother tongues, get unequal access to power and resources e.g. educational, economic and political etc.

Education is perceived to be the gateway to accessing valued resources in today's society. In modern nations, educational attainment has been linked to social and economic well-being of individuals and groups. For this reason, education is especially politicized in nations of pronounced social inequality (particularly in those with multiethnic and multilingual communities), because, equality of education, among other things, is integral for social equality.

In addition, some governments ascribe to the "language as a problem" orientation, taking the position that a common language is one of the most effective strategies to forging a common identity from its multiethnic and multilingual community. Language planning thus assumes great importance. Among the many instruments wielded by governments in language planning exercises, education (in the form of MOI) is one of the most efficient in establishing a hierarchy of languages and prescribing its domains and functions.

Underlying decisions on MOI, are political, social and economic agendas that aim to protect the interests of particular social, political or ethnic groups (usually the dominant group) (Deng \& Gopinathan, 2006, p.614). MOI policies thus tend to become sites of tensions between competing agendas, as well as an arena where power struggles between different ethnic or interest groups in the community are played out (p.614). These competing agendas and tensions have resulted in certain nations adopting "languages of wider communication" (usually English) as the MOI, while others prefer an indigenous language (usually, the dominant language) or a combination of different languages as MOI (Kaplan \& Baldauf, 1998, p.358).

Many nations that sought to adopt "languages of wider communication" as the dominant MOI are often newly independent former colonies. The rationale behind such decisions is often due to instrumental and pragmatic reasons, namely a) to nation- build in terms of economic capacity so as to compete in the global marketplace and b) to forge a common language among a multiethnic population (on the basis of its perceived 'neutral' quality as it is not the mother tongue of any of the groups, thus offering equal access to 
resources for all members of the different ethnic groups). The negative ramifications of adopting "languages of wider communication" as the dominant MOI in postcolonial countries are far-reaching in both spread and depth, encompassing the realms of academic, social, economic and political (Phillipson, 2001, p.196).

Alternatively, in some nations, the indigenous language is constituted as the national and official language (as well as the dominant MOI in schools) so as to redress historical inequalities, through altering the privileged status associated with the colonial languages and thereby, reducing inequalities among the different interest or ethnic groups in the country (Deng \& Gopinathan, 2006, p.612). The promotion of vernacular education is also tied to the need for the preservation of local cultures and serves to contribute to the development of traditional cultural values and social cohesiveness (p.620). Likewise, vernacular education has several negative implications too. In short, education is and has always been, wielded as a tool by those in power to serve their interests. It is often politically motivated, and closely linked to issues about local governance (including ethnic management), political stability and social control (p.621).

\section{AMENDMENT TO THE EDUCATION ACT}

In a startling turnabout to its post-independence educational philosophy, the Malaysian Government (in 2002) amended the education act. The new policy dictated that the teaching of Mathematics and Science would be conducted only through the medium of English, regardless of the language medium of the schools, and it was to be implemented at all levels (MOE, 2004, p.39). The language medium for Mathematics and Science in national examinations would be in English and Mother Tongue (Malay, Mandarin or Tamil), though it would be restricted to only English after 2008 (Ye \& Yu, 2007, p. 2-3). The policy change was a top-down decision, and took place swiftly. However, it would be due for a review in 2008 (Gills, 2005, p.38).

\section{IMPLEMENTATION IN CHINESE NATIONAL-TYPE SCHOOLS}

Under the new educational policy, English and mother tongue (Mandarin) are both used to teach Mathematics and Science in Chinese national-type schools, starting from 2003 (p.4). As such, there would be two periods of English as a core subject, four periods of Mathematics in English and three periods of Science in English (the so-called 2-4-3), in addition to the teaching of Mathematics and Science in Mandarin in lower primary. In upper primary however, there are six periods of Mathematics in Mandarin, two periods of Mathematics in English, with three periods of Science in Mandarin and two periods in English (6-2-3-2) (Nanyang Siang Pau, 23/12/2005, n.p). Meanwhile national and Tamil-medium schools teach Mathematics and Science only in English (Nanyang Siang Pau, 31/10/2002, n.p). 
Upon implementation of the new policy (with its 2-4-3 and 6-2-3-2 schemes), out of five major subjects that the Chinese primary school teaches, only one subject is taught solely in mother tongue (Mandarin), whereas four subjects (Malay, English, Mathematics and Science) are in languages other than mother tongue (Nanyang Siang Pau, 30/7/2002, n.p). Similarly, the amount of time spent attending lessons using Mandarin as the MOI has declined greatly under the 2-4-3 and 6-2-3-2 schemes.

This policy is thus a huge blow to mother tongue education in Malaysia. The ethnic Chinese minority group's linguistic rights, that they had so desperately tried to protect, had been infringed upon and revoked (SkutnabbKangas, 2006, p.274). Yet, it was a decision into which they had no input and which they could not change. This latest threat of assimilation resulted in a huge overhaul of their school and educational system, so that changes brought about by the 2002 Amendment to the Education Act, could be accommodated. It is not surprising therefore, that is a huge outcry from the ethnic Chinese minority, for underlying these changes is the threat of assimilation, in short, the marginalization of Chinese education, identity and culture.

As the 2002 Amendment to the Education Act is due for a review in 2008, the struggle over linguistic rights in MOI policy would only intensify, and one can only speculate on what the future might hold for Chinese minority education and identity.

\section{PURPOSE OF THE STUDY}

In Malaysia, the ethnic Chinese minority (as part of their rights granted in the National Constitution) 'enjoyed' certain linguistic and educational rights, despite the prevalence of discriminatory practices. Theoretically, the Chinese minority has access to education in the dominant Chinese language - Mandarin (Ho \& Wong, 2004, p.222). As such, the 2002 policy contravenes this linguistic right of the Chinese minority, for it demands that Mathematics and Science be taught in English. Hopefully, this study can raise awareness of and offer insights into the relationship of language policy and education for the ethnic Chinese minority in Malaysia, and thereby, provide opportunities for a more enlightened educational environment.

The two education systems (national and Chinese national-type schools) are vastly different; hence, the policy assumes different forms in the two different systems. The Chinese national-type schools thus faced a different set of challenges. By bringing to the forefront, the specific experiences of the various Chinese stakeholders with regard to the policy, I hope to provide knowledge that would raise the policymakers' awareness of the challenges and/or oversights in the planning and implementation of this policy, so that they can better respond to current or future challenges that this policy (or a revised version of it) poses for the ethnic Chinese minority in Malaysia. In addition, the insights gleaned from this study, could assist in improving the planning and 
implementation process for a revision of 2002 Amendment to the Education Act. For the ethnic Chinese minority, I hope that the analysis of the policy and the resultant changes to the Chinese education system can raise awareness of the assimilatory pressures inherent in the policy.

Most importantly, the 2002 policy change is fairly recent and full implementation will only be completed in 2008 . There is thus a paucity of research in this area. This historical moment, therefore, offers a timely opportunity to contribute to existing literature on bilingual education in Malaysia.

\section{METHOD}

A case study methodology was chosen to analyse the 2002 Amendment to the Education Act, with respect to Chinese-medium education. For my research purposes, methodological triangulation was adopted. I employed the use of surveys, interviews and document analysis, with the first instrument being the principal data-collecting tool, while the other two are used as supplementary tools. As my goal was to study the implications of the amended education act, I surveyed Chinese students and parents using questionnaires. Their responses allowed me to gather quantitative information on the perspectives and responses of two groups of participants directly affected by the educational policy. In addition, the informal discussion conducted with two educators furnished me with in-depth perspectives on the policy. I supplemented the primary data I obtained from the surveys and the discussion, with data acquired from document analysis. I drew on data from Mathematics and Science textbooks, newspaper articles and a school climate survey. The quantitative aspect (surveys of parents and students) yielded data that provide for generalizability, whereas the qualitative approach (discussions and document analysis) permitted the gathering of data that offers an in-depth 'look' at individuals, contexts or settings (Creswell, 2008, p.558). Adopting the case study approach provided for a more complete and accurate understanding of the topic and enhanced credibility of results due to the use of multiple instruments etc (Lodico, Spaulding \& Voegtle, 2006, p.286).

\section{SAMPLES}

The sample for this study was chosen through purposive sampling. 42 Chinese upper primary students from a small, urban Chinese national-type primary school were surveyed. The selection of the students rests on three determining factors. Firstly, these must be Chinese students enrolled in Chinese national-type primary schools, although there are non-Chinese students in the schools who could not be included in the sample. Secondly, they must have enrolled in primary school after the implementation of the new policy, so the implications are directly manifested in their attitudes and responses. Lastly, they must be at 
least Primary or Grade 4, as older students are more likely to be capable of responding to the survey questions with understanding.

The second portion of my study explored parents' responses and beliefs. The survey posted responses from 27 Chinese parents. The first determining factor was that they must have children who are currently enrolled in Chinese national-type schools, as they are then directly affected by the change in education policy. Second, they must have attended Chinese national-type schools previously, so they can compare their own learning experiences to their children's.

Discussions were also conducted with a Chinese teacher and principal from the school. Both educators had taught (Mathematics and Science in addition to other subjects) in Chinese national-type primary schools for a number of years. One of the educators was educated through first Mandarin, then Malay as MOI, whereas the other was educated primarily in English as MOI (during pre and early independence).

As for documentary evidence, a school survey conducted by the United Chinese School Teachers' Association (Dong Jiao Zhong) was included, as well as an examination of newspaper evidence spanning five years, starting from May 2002 when the amended education act was first introduced, to April 2007. The newspaper articles (totaling 899) were collated from Nanyang Siang Pau (a Chinese-Malaysian newspaper owned by the investment arm of the Chinese branch (MCA) of the ruling political party in Malaysia). A content analysis of four Science and Mathematics textbooks, in use in Chinese national-type primary schools, was also undertaken. The textbooks selected were drawn from Primary 5, and consist of both English and Mandarin versions. The various data (as described above) were collected in the summer of 2007.

\section{RESULTS}

\section{Challenges unique to Chinese schools}

Findings from the sources listed above -educators, parents, students, textbooks and newspaper articles- were obtained and cross-analysed. Several themes emerged from the findings. Firstly, the data indicates that the resultant challenges of the 2002 amended act are unique to Chinese schools. Chinese schools, as a consequence of the new educational policy, have to cope with challenges in completing the Mathematics and Science syllabus, repetition of Mathematics and Science lessons and marginalization of Mandarin and Chinese schools' identity.

According to the analysis of newspaper articles, "difficulties in completing the syllabus" is cited as one of top three problems that the implementation of the new education policy poses for Chinese schools. This finding is corroborated by the DJZ survey that found that $81.6 \%$ of the schools expressed that the teachers' teaching time was insufficient as a result of the reduction in teaching periods of Mathematics and Science with Mandarin as the 
MOI. The teachers had to rush through the syllabus, affecting students' learning progress in Mathematics and Science. The teachers could not finish the syllabus as the content has remained the same though the periods had been drastically reduced.

In addition, the repetition of the lessons in both Mandarin and English is a major impediment to the effective teaching and learning of Mathematics and Science, as identified by the newspaper articles. As described by an article, often the contents in the Mandarin textbooks are a translation of the English version (Nanyang Siang Pau, 4/3/2003, n.p). As evident in the analysis of the different language-medium Mathematics and Science textbooks, the respective textbooks are the same in terms of crucial elements such as topics, concepts and skills taught, differing mainly in stylistic elements. Thus, it is not inconceivable that $40.4 \%$ of the schools surveyed highlighted that their students felt bored and lost interest in learning, with the repetition of the Mathematics and Science lessons in English and Mandarin. $60.3 \%$ of the schools too felt that the repetition of the lessons in different languages caused the students to feel confused and hindered the students' learning progress.

The difficulties in completing the syllabus and the repetition of lessons contributed to an increasing marginalization of the Chinese language, which consequently posed a challenge to the maintenance of the Chinese character of the Chinese national-type primary schools. After the implementation of the policy, nearly half of the subjects are taught through the medium of Malay or English (Nanyang Siang Pau, 30/7/2002, n.p). Moreover, the number of periods in which Mandarin is used as the MOI had also dramatically decreased. It is therefore not surprising that $72 \%$ of the schools commented that the reduction in the number of periods in mother tongue had directly affected the students' learning, resulting in diminishing mastery of Mandarin. According to $41.1 \%$ of the schools surveyed, students' stress had increased as a result of additional time and effort spent in acquiring English and the learning of Mathematics and Science in English, resulting in a decline in interest in learning Mandarin. The increasing marginalization of Mandarin, induced fears in the Chinese community that the differences between Chinese national-type and national schools were being gradually diminished. Indeed, this fear is well-founded as the parent survey showed that there is an equal number of parents $(48.1 \%)$ who would prefer to enroll their children in Malay nation schools, compared to Chinese national-type schools.

The implementation of this new policy has brought about huge changes to the current educational system in the Chinese schools, and a unique set of challenges. In an effort to ensure the success of this change in policy, the Ministry of Education had instituted a series of measures to support schools and teachers (as described below). 


\section{Support for schools}

Three notable types of support emerged from the findings. Teacher training, provision of teaching resources and peer support (through mentoring scheme) are areas which the Ministry focused heavily on. In an effort to improve the quality of teaching for Mathematics and Science in English, the Ministry of Education employed international consultants, provided training courses, gave monetary incentives, hired local trainers, as well as deputizing a portion of the teachers as 'master teachers' to train their peers. Despite the abundance of training and the huge investments in time, efforts and funds, the training program has its flaws. Logistical problems, unfair distribution of monetary rewards and the questionable qualifications of some of the trainers are some of the kinks that still need to be ironed out.

The Ministry of Education, to supplement their training programs for the teachers, also allocated huge sums in funding to schools, as well as provided teachers with computer software and ICT equipment to assist in the teaching of Mathematics and Science in English (Nanyang Siang Pau, 3/1/2003, n.p). Additionally, they developed pertinent software and non-ICT resources for teachers and schools (Nanyang Siang Pau, 28/7/2003, n.p). However, problems with the teaching resources were commonplace, e.g. over-reliance of ICT equipment, problems with operating the equipment, the incompatibility of the resources for Chinese national-type schools etc.

The mentor system is another form of support touted by the Government as a strategy to 'patch up' the deficiencies in the teacher training program. Mentors would provide aid to teachers teaching Mathematics and Science in English. In conjunction, they would also conduct an English evaluation of their peers. Teachers who failed their evaluation would have to participate in retraining programs (Nanyang Siang Pau, 11/4/2007, n.p). This enforced assessment of teachers teaching Mathematics and Science (in English) is likely to add to the psychological burden and stress of the already beleaguered teachers, as commented by $72.7 \%$ of the schools surveyed by the DJZ, who are already suffering from having to invest more time into lesson preparation and the use of English as MOI.

It is apparent from the evidence that the Ministry adopted a 'one-size fits all' approach towards provision of support. The Chinese schools' unique characteristics and the differential forms (2-4-3 and 6-2-3-2 schemes) that the policy assumes (in the Chinese primary schools) are not taken into consideration.

\section{Political compromise versus language rights: a community's response}

Consequently, dramatic changes swept through Chinese schools like a bonfire and the ensuing host of challenges brought about a maelstrom of vehement responses from the Chinese community. Data obtained point to three principal groups that are directly affected by the policy: educators, students and parents. 
For the Chinese educators, the change in policy has resulted in challenges that are unexpected, and which they and their schools are not equipped to deal with. It also brought changes that could have far-reaching (and potentially disastrous) consequences for the existence and identity of Chinese schools and education, as well as for Chinese students' progress and academic performance. Thus, for the reasons cited above, most Chinese educators objected to the implementation of the new policy in Chinese schools, though they did agree with the need to improve English standards in Malaysian schools.

The changes also had an impact on student learning and perspectives. Findings indicated that the majority of the Chinese students had difficulties adjusting to English as the MOI for Mathematics and Science, and performed inadequately when they are instructed or assessed through English (as compared to Mandarin), hindering their learning progress in the process. It is obvious that mother tongue education is preferred as it is the most effective and direct language medium for educating children.

As for the Chinese parents, the majority felt ambivalent about the latest change in education policy. They objected to the use of English as the MOI and advocated for a return to mother tongue education, rightly fearing a deterioration of their culture and linguistic rights. Yet, they could not deny the increasing importance of English in the global arena, an issue that they dealt with by providing their children with support outside of school. It is also an issue that the Chinese community is grappling with - that is, the best way to retain their heritage and linguistic rights, while keeping up with the pace of globalization and Anglicization.

\section{DISCUSSION}

Often, political motivations play the primary role behind MOI policies, especially in multi-ethnic societies (Deng \& Gopinathan, 2006, p.614). One of the more common political agendas behind MOI planning for a multi-ethnic community, is the assimilation or integration of the minority group into 'mainstream' society for purposes of ethnic management (p.621). The inability to complete the syllabus and the repetition of lessons can be construed as consequences of attempts by the Government to ensure that the Chinese students are being gradually assimilated through education. Initially, the plans for the new policy with respect to Chinese schools, only involved the removal of a few periods from the curriculum to teach Mathematics and Science terminology in English. However, this initial plan, to assure that Chinese students are not 'left behind' compared to their Malay and Indian counterparts, came to assume a political hue. The Chinese students are forced to undergo the same teaching (as their national school brethren) through adherence to the same syllabus and usage of the same textbooks, though there are fewer periods allocated to the teaching of Mathematics and Science in English (in Chinese schools). In addition, they are already being taught the same syllabus and content in their mother tongue. In 
face of such handicaps in logistics and teaching (periods allocated, common syllabus and textbooks and repetition of lessons), teachers and students suffered immensely, in teaching and learning.

It is evident from the data collected, that it is difficult for many teachers to complete the syllabus given the lack of time and the volume of content to be taught. In addition, the training given to the Chinese teachers did not prepare them adequately for teaching Mathematics and Science in English (in the Chinese schools), culminating in an environment in which teaching is uninspired and possibly open to misinterpretations. It also contributed to challenges in completing the syllabus by virtue of the frequent removal of teachers from the classrooms and schools for training. Already suffering from the psychological burden of teaching in a foreign language medium, teachers also had to expend more time and energy on lesson preparation and teaching in English. Coupled with that, the Ministry's assessment of teachers' English proficiency is an unnecessary burden to the already beleaguered teachers. It is therefore not surprising that a sense of inadequacy and helplessness pervade the teaching of Mathematics and Science in Chinese schools. Standardization for purposes of assimilation has resulted in enormous challenges for teachers.

For students, the lack of time (due to the number of periods allocated) has resulted in a situation whereby completing the syllabus outranks student' understanding of lessons. It is thereby to be expected that students' learning would be affected, as there is insufficient time for students to process and learn what was taught. Another factor that affected students' learning, is the inadequate training offered to Chinese teachers, something that subsequently influenced the quality of teaching. The repetition of lessons (albeit using a different language) also adds to the students' boredom as well as decreasing their motivation. As Cardenas and Carrasquillo have noted, mother tongue education provides students with a strengthened self-concept and the necessary motivation to learn (as cited in Chandler, 1992, p.83). Conversely, education through a foreign tongue diminishes the motivation to learn. Not only is incomprehensibility an issue, initial adjustment difficulties (i.e., lower academic performance) also contribute to a lack of motivation to learn. Ultimately, the drive to integrate the Chinese students into mainstream society, is in actual fact posing barriers to student learning, and attempting to marginalize them.

The various challenges discussed above are only a part of the hidden political agenda to integrate or assimilate the Chinese community through education. According to Lindgren (2000), the institution of a linguistic hierarchy is one of the initial steps towards the assimilation or integration of minorities (p.40). Another crucial integration or assimilation mechanism is the restriction of the domains in which the minority tongues are used (Baker, 2006, p.83). These two objectives are readily apparent in the 2002 Amendment to the Education Act. According to an analysis of the findings, the new policy has sought to position Malay and English as the two main languages of Malaysian 
society, striving to push the positions of Mandarin and Tamil languages down to the second or third rungs on the hierarchical language ladder. Out of the five subjects assessed in UPSR (Primary 6 National Examination), only one is conducted solely in the medium of Mandarin. Furthermore, most of the nonexaminable subjects are taught through the medium of mother tongue, subtly signifying the 'low' instrumental value of the mother tongue, and teaching minorities to despise their own languages (culture) when it is not given a position of prominence in education (Chandler, 1992, p.83). The above descriptions are trademarks of a transitional bilingual education, with the objective of language shift, which appears to be a high possibility under such circumstances.

Under the new policy, the use of Mandarin (or mother tongue) in Chinese schools, to teach different subjects has steadily decreased. Additionally, Mandarin as a core subject has also seen its teaching time gradually decreasing. These new features are indicators of the carrot component of the 'stick and carrot' approach that Skutnabb-Kangas (2000) describes in her discussion of the experiences that ethnic minority groups undergo when they are pressured to assimilate or integrate. The institution strives to assimilate the Chinese minority group through persuasion (of the benefits of English for the general populace as well as for the Chinese community), ideas of traditionalism and uselessness in regards to the mother tongue (through the institution of a linguistic hierarchy in which Mandarin ranks below English and Malay) and positive reinforcement in relation to the dominant culture and language (through the provision of funding and resources for English teaching of Mathematics and Science) (p.130-1). There is thus grounds for "illiteracy of oppression" (a direct consequence of the process of assimilation or integration at work) to occur, in which the minority ethnic group's identity and means of resistance are often slowly destroyed (Van Deven, 2006, p.42). Furthermore, the new features introduced in Chinese national-type primary schools have resulted in the blurring of lines of distinction between the national and Chinese schools, a surefire strategy to erode the Chinese school's identity. In future, Chinese schools would no longer be the bastion for defending Chinese education and the Chinese community's heritage and culture.

As to the effect the new policy has on Chinese students' learning and academic performance (if any), Cummins' interdependence hypothesis appears to suggest that use of mother tongue as the MOI can build on the less than fully developed linguistic and intellectual skills of the students on entry to school (Cummins, 2001, p.79). Students will thereby, be able to benefit fully from interaction with the teacher, and enjoy access to the cognitive-linguistic operations necessary to assimilate the L2 and develop concepts and knowledge taught through L2. Following this presupposition, Chinese students' cognitive development would surely be negatively affected if the MOI is no longer the mother tongue, thereby posing obstacles to their learning and consequently, 
lowering academic performance. The data appear to corroborate the literature. The quality of learning and interaction appear to be negatively affected when English is used as MOI as compared with when lessons are conducted in Mandarin. Difficulties in adjustment have also resulted in poor academic performance of the Chinese students, when instruction is through the medium of English. Additionally, the stress from adjusting to English as the MOI has also taken its toll on the learning of Mathematics and Science in Mandarin, for data obtained revealed that Chinese students' Mathematics and Science academic performance has suffered, even when the language of instruction is in Mandarin.

In regard to the effects of the policy change on Chinese schools, the findings clearly indicate that the amended education act has affected the Chinese community greatly, striking hard at one of the last bastions of Chinese identity and heritage. This new policy has chipped away at one of the 'sacred pillars' that upheld an agreed upon constitutional right of the minorities to their language and education in their mother tongue. Not only is the very essence of Chinese schools and education affected by the multitude of changes that accompanied the amendment to education policy, the proliferation of challenges arising from these changes has culminated in an un-conducive environment for both teaching and learning.

Regarding the response and perceptions of the various Chinese stakeholders towards the new policy, concerns about preserving their particular identity from perceived external threats (such as assimilation or integration) often elicits in the minority Chinese groups, a desire to maintain their language and culture (Chandler, 1992, p.21). As stated by Skutnabb-Kangas (2000), when an ethnic group's language is threatened, its cultural and linguistic survival is at stake, and most importantly its existence as a group, a people (p.436). Thus the 2002 Amendment to the Education Act, with its attempts to replace Mandarin (the mother tongue) with English as the MOI, has aroused vociferous responses from the Chinese community, who perceive it as the latest threat in a long series of attempts to assimilate or marginalize their community. As observed from the data, many Chinese educators felt the burden of teaching in a foreign tongue, with the accompanying increase in workload and inadequate support, not to mention stress. These unwarranted stressors, coupled with the challenges that the new policy has created for Chinese schools and their education systems, have led Chinese educators to believe that the policy is not planned with educational considerations in mind, and instead, is an instrument of assimilation or marginalization. This belief is particularly relevant as the data reveals that the policy would lead to the narrowing of differences between national and Chinese national-type schools, thereby diminishing Chinese schools' uniqueness and attractiveness, and positioning the national schools as a comparable or attractive option for Chinese students. It is also indicated from the findings, that a small number of educators and members of the Chinese community appears to have 'bought into' the promises that the Malay-dominant Government has given 
regarding the benefits of the policy for the Chinese populace as well as the rest of the Malaysian community. The division of the Chinese community into two camps of opinions and beliefs, had resulted in vehement opposition by the majority of the Chinese educators towards the new educational policy, as they feared it would be potentially devastating to the continued development of Chinese schools and education, and would undermine the Chinese heritage. In addition, they feared negative implications for Chinese students. Thus, most Chinese educators are insistent on reinstating mother tongue as the MOI in Mathematics and Science teaching and assessments, and call for Government to rescind the 2002 Amendment to the Education Act. They argued that the Government should not 'politicize' the issue, but rather should look at it from an educational standpoint.

Students' beliefs and responses play a big factor in parental support or lack thereof for the new educational policy. The data show that, instrumental value of a language ranks very high with parents. There is thus a possibility that parents would 'buy into' the 'English as a valuable economic commodity and resource' argument that the Government is basing its new education policy on. Consequently, Chinese parents may end up being 'consenting' partners in the gradual marginalization and assimilation of Chinese education and schools, through enrolling their children in national schools (where they perceive their children would be afforded equal or better access to the curriculum, and thereby better equipped to function in an increasingly Anglicised environment). On the other hand however, most parents are opposed to the use of English as the MOI as they are justifiably worried about the negative implications of the policy for Chinese schools and education. The deliberations on the fate of the 2002 Amendment to the Education Act, would probably help end the Chinese parents' ambivalent position. The parents' opinions and responses could swing either way on the pendulum after 2008 .

Finally, with regard to the implications of the change in education policy for Chinese education, data reveal that, in general, the perspectives and responses of the Chinese community have been unfavourable towards the new educational policy. There has been cause for the Chinese community to believe that the character and integrity of Chinese schools and education have been compromised. In addition, they sensed a threat to the continued survival and development of Chinese education and schools. There also seems to be a consensus among the majority of the Chinese population that Chinese education would forever be changed by this one single act, which opens the floodgates to further assimilation attempts.

\section{CONCLUSION}

Based on the findings from the study and the educational measures that the Ministry of Education instituted, it is probable that the 2002 Amendment to the Education Act is here to stay, though the forms that it may assume, may vary. 
Public pressure may result in some 'cosmetic' changes to the policy, but the very essence of the educational policy would remain unchanged. It is apparent from the evidence examined, that the Government has not given up, and has and will consistently pursue the goal of assimilation, with regard to the Chinese ethnic minority. Therefore, Chinese education and schools will continue to face an onslaught of education policies, with the twin agendas of marginalization and assimilation. The 2002 Amendment to the Education Act will not be the only or the last assimilation tool that the Government of Malaysia will wield. It is the harbinger of a new era in Chinese education and schools, where struggles between the majority group and the ethnic minority Chinese group will intensify, as Malaysia becomes increasingly battered by both global and local pressures.

\section{POSTSCRIPT}

In July 2009 after much public protest against the language policy, the Minister of Education, Muhyiddin Yassin reported that the requirement that Mathematics and Sciences be taught in English would be reversed because academic results in Mathematics and Science had declined since introduction of the English language requirement for those subjects, and as of 2012, the language of instruction in Mathematics and Sciences would be the mother tongue.

\section{References}

Baker, C. (2006). Foundations of bilingual education and bilingualism $\left(4^{\text {th }}\right.$ ed). Clevedon, Buffalo, Toronto, Sydney: Multilingual Matters Ltd.

Chandler, M. T. (1992). Toward a context-specific language policy for developing countries with an emphasis on language-in-education. Thesis for Biola University, 1-194.

Collins, A. (2005). Securitization, Frankenstein's monster and Malaysian education, The Pacific Review, 18(4), 567-588.

Creswell, J. W. (2008). Educational research: Planning, conducting, and evaluating quantitative and qualitative research. New Jersey, Pearson Education Inc.

Cummins, J. (2001). Linguistic interdependence and the educational development of bilingual children. In Baker, C. \& Hornberger, N. H. (Eds.) An introductory reader to the writings of Jim Cummins. Clevedon, Buffalo, Toronto, Sydney: Multilingual Matters Ltd.

Deng, Z. Y. \& Gopinathan, S. (2006). The complicity of medium-of-instruction policies: Functions and hidden agendas. Journal of Curriculum Studies, 38(5), 609-622.

Gills, S. K. (2005). Language policy in Malaysia: Reversing direction. Language policy, (4), $241-$ 260. 
Ho, W. K. \& Wong, R. Y. L. (2004). Language policies and language education: The impact in East Asian countries in the next decade. Singapore: Eastern Universities Press.

Kaplan, R. B. \& Baldauf, R. B. (1998). The language planning situation in ...Journal of Multilingual and Multicultural Development, 19(5\&6), 358-367.

Kee, W. H. (1971). The development of a national language in Indonesia and Malaysia, Comparative Education, 7(2), 73-80.

Lindgren, A. (2000). Language emancipation: The Finnish case. In Phillipson, R. (Eds.) Rights to language: Equity, power and education. Mahwah, USA: Lawerence Erlbaum Associates, Inc., Publishers.

Lodico, M. G., Spaulding, D. T. \& Voegtle, K. H. (2006). Methods in educational research: From theory to practice. San Francisco: Jossey-Bass.

Malaysia Ministry of Education (MOE) (2004). The development of education: National report of Malaysia.

Nanyang Siang Pau. (2002, May, 19th). 韩春锦指英语教数理，只考虑国小实行

[Han Chunjin points out that the use of English to teach Mathematics and Science, is only considered for implementation in national primary schools.] Retrieved December 5, 2007, from http://archive.nanyang.com/index.php?ch=7\&pg=12\&ac=150200

Nanyang Siang Pau. (2002, July, 30th). 校友联总坚持立场,华语教授华校数理 [School Alumni

United Association stand firm on the issue of use of mother tongue to teach Mathematics and Science.] Retrieved December 6, 2007, from

http://archive.nanyang.com/index.php?ch=7\&pg=12\&ac=171299

Nanyang Siang Pau. (2002, October, 23rd). 华基政党有信心,将达致圆满方案

[Chinese political parties have confidence in coming to a mutual agreement.] Retrieved

December 10, 2007, from

http://archive.nanyang.com/index.php?ch $=7 \& p g=12 \& a c=195718$

Nanyang Siang Pau. (2002, Oct, 31st). 增设英文词汇解决争端,华小续母语教数理

[Adding English vocabulary to resolve disputes, Chinese primary schools to continue the teaching of Mathematics and Science in Mother Tongue.] Retrieved December 10, 2007, from http://archive.nanyang.com/index.php?ch=7\&pg=12\&ac=198004

Nanyang Siang Pau. (2003, January, 3rd).中小校获教育部提供, 英文教数理科教学器材 [Primary and Secondary Schools are allocated English resources for the teaching of Mathematics and Science.] Retrieved Deccember 11, 2007, from http://archive.nanyang.com/index.php?ch=7\&pg=13\&ac=214257

Nanyang Siang Pau. (2003, March, 4th). 一数理英文词汇课本, 待教部通过科明年推出 [Primary

One Mathematics and Science vocabulary in English textbook, to await Ministry of Education's approval for publication next year .] Retrieved December 12, 2007, from http://archive.nanyang.com/index.php?ch=7\&pg $=13 \& \mathrm{ac}=232289$

Nanyang Siang Pau. (2003, July, 28th). 没善用提升英文能力教材, 教师漠视学习指南 [Teachers did not fully utilize English language teaching resources and ignore teaching guide.] Retrieved December 12, 2007, from http://archive.nanyang.com/index.php?ch=7\&pg $=13 \& a c=278052$

Nanyang Siang Pau. (2005, December, 23th). 黄家定 : 符合华社与家长意愿

[Huang Jiading announces new scheme meets Chinese community's and parents' wishes.] Retrieved December 28, 2007, from http://archive.nanyang.com/index.php?ch=7\&pg=15\&ac $=564763$

Nanyang Siang Pau. (2007, April, 11th). 繁文桭节, 校方吃不消

[Too many formalities, schools are unable to cope.] Retrieved January 2, 2008, from http://archive.nanyang.com/index.php?ch=7\&pg $=175 \& a c=718167$

Phillipson, R. (2001). English for globalisation or for the world's people? International review of Education, 47(3-4), 185-200. 
Skutnabb-Kangas, T. (2000). Linguistic genocide in education or worldwide diversity and human rights. Mahwah, New Jersey: Lawrence Erlbaum Associates, Publishers.

Skutnabb-Kangas, T. (2006). Language rights and linguistic rights. In Ricento, T. (Eds.) An introduction to language policy: Theory and method. Massachusetts, USA, Oxford, UK, Victoria, Australia: lackwell Publishing.

The Star. (2009, July, 8th). Math and Science back to Bahasa, mother tongues.

Retrieved July $11^{\text {th }}, 2010$, from

http://thestar.com.my/news/story.asp?file $=/ 2009 / 7 / 8 /$ nation $/ 20090708144354 \&$ sec $=$ natio $\underline{\mathrm{n}}$

Van Deven, T. L. (2006). The Native-English Teaching Program in Hong Kong, China: A critical ethnography, 1-234.

Ye, H. J. \& Yu, Y. Z ed (2007). The suitability of English Teaching of Mathematics and Science. Malaysia: The United Chinese School Teachers' Association of Malaysia

Charissa Soek Yee Chan teaches at St. Margaret's Primary School in Singapore. Her research interests include post-colonialism and language education. She can be reached at chan_soek_yee@moe.edu.sg. 